\title{
The intra-spousal balance of power within the family: cross-cultural evidence
}

\author{
Pierre-André Chiappori
}

Columbia University

\author{
José Alberto Molina
}

University of Zaragoza and IZA

\begin{abstract}
This paper examines cross-cultural evidence of the intra-spousal balance of power within the family. The traditional, 'unitary' model of the family, which assumes that members maximize a single utility function, has increasingly been challenged in recent decades, as a consequence of a questioning of the underlying income-pooling hypothesis, through attempts to assume differential preferences of family members, with the relative power of spouses being of particular significance. These non-unitary models treat family decisions as outcomes of interactions between the spouses. We focus here on collective models, which have been most widely used for that purpose. We show international evidence on the basis of the UN Human Development Index 2018. Data results indicate that, in both developed (very high and top medium HDI) and non-developed (bottom medium and low HDI) cultural areas, non-unitary models, in which intra-spousal bargaining power plays a role, are empirically accepted. The Pareto-optimality hypothesis of collective models has been accepted for most statistical data bases. In developed cultural areas, wives, on average, control between one half and two thirds of household resources, with the highest bargaining power affecting expenditure patterns. As the bargaining power of women grows, allocations to education and school attendance also tend to grow in most countries.
\end{abstract}

Keywords: Cross-Cultural; Intra-marriage; Balance of Power; Non-unitary Models; Pareto-efficiency

This document was mainly written while Jose Alberto Molina was Visiting Professor at the Department of Economics of Boston College (US), to which he would like to express his thanks for the hospitality and facilities provided. This work has been partially supported by the Government of Aragon (Project S32-17R) and FEDER 2014-2020. 


\section{INTRODUCTION}

A cultural area can be identified as a geographical area with one relatively homogenous human activity, or with individuals sharing common cultural characteristics. The organization of human communities into cultural areas and, consequently, crosscultural analyses, are common practices throughout the social sciences. Individuals in a cultural area may speak the same language, practice the same religion, share the same customs, live under similar systems of livelihood, and generally have more contact with each other than with those outside their own cultural area.

This paper adopts an economic perspective to analyze cross-cultural evidence of the intra-spousal balance of power. The family unit is, according to the Nobel Laureate economist Gary Becker, the decision-making unit linked through kinship that constitutes society's greatest treasure, in terms of its capacity to generate individual and social welfare. The economic studies of family issues, originally carried out from a descriptive perspective, are now appearing in rigorous economic models that develop detailed analyses, from both internal and external perspectives.

We wish to emphasize that the detailed study of the socio-economic behavior of families in society is, in recent decades, another way of looking at the social consequences of economic constraints on individual behavior and we concentrate on the basic idea that there are substantial benefits to individuals from living in couples. Individuals gain from sharing goods within the household, and can take advantage of specialization, resulting in a comparative advantage in home or market production. Individuals in a household can pool income risk, sharing in each other's gains and insuring one another against shocks 
(e.g. poor health or job loss). Most importantly, individuals in a household can jointly invest in their children.

Family empirical analyses have, traditionally, been based on the unitary model that assumes that family members maximize a single utility function (Samuelson, 1956; Becker, 1981). This is based on the assumption that the family acts as a single unit with specific and well-defined preferences. Various justifications have been given for that assumption. For Samuelson, individual preferences are merged at marriage into a common index. However, as pointed out by Becker, the index is simply postulated in a somewhat ad hoc fashion; nothing is said about its generation. In particular, Samuelson explicitly posits that the index is independent of individual incomes - an assumption that is needed for the traditional tools of consumer theory to apply at the household level, but is hard to reconcile with any representation of family decision-making process that entails bargaining between members. Becker himself, in his well-known 'Rotten Kid' theorem, provides an alternative justification based on game theory. However, his approach relies on very strong assumptions, regarding both the distribution of power within the family (a 'benevolent patriarch' must be the ultimate decision maker) and the nature of individual preferences (utility must be transferable, in such a way that one individual can transfer part of its utility to another one in a costless way, which requires that individuals have a common 'currency' that is valued equally by all; see Bergstrom 1989).

The unitary model has strong empirical implications for family behavior. In particular, it requires that individual members pool their income in achieving family outcomes in such a way that the identity of the income recipient is of no consequence for the family's behavioral outcomes. In this traditional unitary model, neither the identity of the income recipient nor the income source has any effect on the family's expenditure allocation; all that matters is total family income. This restriction has raised some questions about the 
validity of the unitary model. Empirically, a series of contributions have clearly rejected it (see, for example, Schultz, 1990; Thomas, 1990; Kanbur and Haddad, 1994; Lundberg and Pollak, 1994; Hoddinott and Haddad, 1995; Lundberg, Pollak and Wales, 1997; Phipps and Burton, 1998; Duflo, 2000; Attanasio and Lechene, 2002; Maitra and Ray, 2002; Maitra and Ray, 2003; Quisumbing and Maluccio, 2003). On the theory side, it essentially ignores the existence of potential complex decision processes within the household, and disregards intra-family inequality.

Consequently, the unitary model has been increasingly challenged in recent decades, through attempts to model individual utility to incorporate the differential preferences of family members, with the relative power of the individual being crucial to these non-unitary models (Pollak, 1994). Such challenges have typically included attempts to model individual utility and to incorporate the divergent and conflicting preferences of different family members through an either explicit or axiomatic representation of intra-household decision process. More general models of family decision-making share a common characteristic: they take the individual as the basic element and treat family decisions as the outcomes of interactions among the members.

Two strands have emerged in the literature. The first line, the so-called 'collective' approach $^{1}$ (Chiappori, 1988, 1992; Browning and Chiappori, 1998; Donni and Chiappori, 2011; Donni and Molina, 2018), that occupies by now a dominant position, is based on cooperative game theory. It either models the decision as the solution to an explicitly described bargaining game (McElroy and Horney, 1981; Manser and Brown, 1980), or simply postulates it as the outcome of negotiations that achieve efficiency, in the sense that no alternative choice would have been preferred by all family members. Note that, since bargaining games typically postulate efficiency, the first specification is a particular

\footnotetext{
${ }^{1}$ See Browning, Chiappori and Weiss (2014) for a general overview.
} 
case of the second. A second direction refers to non-cooperative game theory, in which there is no possibility to manage alliances, given the selfish behaviors of individuals, with this theory being specifically applied to the topic of private contributions to public goods (Konrad and Lommerud, 1995; Doepke and Tertilt, 2017). Lastly, some works try to establish a bridge between the two approaches, for instance by taking the non-cooperative solution as the status quo point for a cooperative bargaining model (Basu, 2006; Kanbur and Haddad,1994; Lundberg and Pollak, 1994).

There is a significant literature, both historical and recent, in sociology and anthropology arguing that spousal power is important in the analysis of family behavior (see, for example, Blumberg and Coleman, 1989; Desai and Jain, 1994; Pollak, 1994; Riley 1997; Kousta, 2019; Slatton and Brailey, 2019). Here, we focus on the economic empirical analyses that have estimated the determinants of spousal power, and have quantified the magnitude of its impact on the various behavioral outcomes of the family.

This paper collects evidence of the intra-spousal balance of power in the nonunitary models, with the collective models à la Chiappori being the most used, but with some results also obtained from the experimental approach. An immediate advantage of the collective approach is that it provides a direct and tractable translation of the notion of power. Theory shows that any efficient decision must maximize a weighted sum of individual utilities; if one accepts this representation, then there exists a direct relationship between the corresponding weights (often referred to as 'Pareto weights') and the respective 'powers' of household members. Hence, unlike the traditional unitary model, any change in a variable that affects the balance of power in the family can impact economic decisions of the family (consumption, labor supply....), even when the family's total income and all prices remain unchanged. In these collective models, the relative power of family members plays a central role in shaping family decisions. Spouses derive 
power from multiple sources, many of which reflect the options an individual has outside the family. We will see during this chapter that many studies have considered the incomegenerating capacity of husbands and wives as measures of their relative power. Other studies have relied on non-labor income, or the value of assets, or other physical or social characteristics of individuals, as alternative determinants of spousal power. Finally, a complementary approach investigates how the intra-household allocation of power is related to global factors, such as legislations governing divorce or property rights or the sex ratio on the relevant 'market for marriage'.

Given the objective of analyzing cross-cultural evidence of the intra-family balance of power, we have identified both developed and developing areas around the world, using the UN Human Development Index 2018. According to this HDI, the US, Canada, Australia, most of Western Europe, South Korea, Chile, Mexico, and Colombia are included in the Very High Human Development category; South Africa and Indonesia are at the top of the Medium Human Development category, while countries from SouthAsia, such as Nepal and Pakistan, and from Sub-Saharan Africa are either at the bottom of the Medium Human Development group, or in the Low Human Development category

The rest of the paper is organized as follows. Section II summarizes the most relevant international evidence in developed cultural areas. Section III is dedicated to evidence of the intra-spousal balance of power in developing regions. Finally, section IV closes the paper with the most important conclusions. 


\section{THE INTRA-FAMILY BALANCE OF POWER: CROSS-}

\section{CULTURAL EVIDENCE IN DEVELOPED AREAS}

Cultural regions are geographical areas in which individuals share common cultural characteristics (Gupta and Ferguson, 1997), and we have identified seven developed areas which show a very high or a top medium HDI; namely, The United States and Canada, Australia, Europe, East-Asia, Latin America, South Africa, and Indonesia, where economic analyses of spousal power in non-unitary frameworks have been developed.

\section{The United States and Canada}

The United States and Canada are often considered as belonging to the same cultural region. The majority language in both countries is English, and both countries were once British colonies. The majority in both countries follows the Christian religion, both were once home to native American Indians and had very large spaces in the West which were gradually settled by pioneers. Citizens in both countries follow similar occupations and enjoy similar ways and standards of living.

For the case of the US, some authors have shown evidence against the hypothesis that a married couple behaves as if governed by a single utility function of one spouse and, consequently, being more consistent with a household model described by, at least, two preferences (Andreoni, Brown and Rischall, 2003; Lundberg and Ward-Batts, 2004; Yilmazer and Lich, 2015), with different topics being analyzed from the intra-family balance of power. 
Expenditures on consumer goods in the family depend on the bargaining between spouses with different preferences. In addition to goods with a clear gender characteristic (clothing or leisure), the bulk of family consumption goods take the form of public goods. One such public good is the family's charitable giving. Andreoni, Brown and Rischall (2003) have identified systematic gender differences with respect to charitable giving, with single men and women being significantly different in their propensities to give, in the amount they give, and in the distribution of those gifts. These differences indicate that women tend to give to a greater variety of charitable entities, giving less to each, in contrast to men, who tend to concentrate their giving among fewer charities. Married women especially favor health and education, while husbands are more generous than wives only within the sphere of adult recreation. These authors have shown that when a particular spouse has sole control, the decisions seem to reflect his or her own tastes. But, when decisions are made jointly, husbands seem to be getting more of what they want than do wives. The authors also found that the probability that the wife controls giving decisions decreases when her husband earns more than she does, or is more highly educated than she, with these two measures (income/earnings and education) being generally associated with bargaining power. Although the marital bargain on charity mostly favors men when it comes to total giving, when women do become the deciders, they wield their power to influence the disbursement of the family's charity. Thus, the authors provide direct evidence to support the growing feeling among fundraisers that men and women behave very differently with respect to charitable giving.

Husbands and wives may have different private interests in savings and wealth accumulation that must be resolved through the household decision process. Lundberg and Ward-Batts (2004) use a collective framework, which includes indicators of the relative control over resources of husbands and wives, to show limited evidence that the 
wife's long-run relative power over household decisions is positively associated with household net worth. Households in which the husband has substantially more education than his wife spear to have significantly lower net worth.

There is limited research on how intra-family financial decisions are made, with prior studies suggesting that women invest their asset portfolios more conservatively than do men, and that it is not gender alone that drives the investment decisions of men and women, but rather a combination of gender and marital status. Yilmazer and Lich (2015) present an analysis of the allocation of assets in family financial wealth, using a nonunitary model where the spouses differ in their risk preferences. The empirical findings using the Human Retirement Survey (HRS) show that families invest more in risky assets as the risk tolerance of the spouse who has greater bargaining power increases. In addition, there seems to be no evidence that bargaining power is related to risk tolerance. These results are consistent across a variety of specifications. This study provides evidence that the risk preference of the decision-maker in the family plays an important role in household portfolio decisions. The decision-maker is, most of the time, the more educated partner, but the literature does not indicate whether the spouse who makes the decision consults, or not, with the other. It can be argued that couples simply think it is wise to rely on the person with the higher education, but this is not bargaining power. However, when the more educated partner gets to make a decision that is in line with his or her preferences, it is still a distributional factor that results in more weight being placed on his or her preferences. This would matter for welfare analysis and predictions regarding the investment behavior of two-person households.

For the case of Canada, evidence using consumption data on couples and singles shows the dominance of the collective model. A recent study, Browning, Chiappori and Lewbel (2013), employs Canadian data to show that couples save the equivalent of about 
one third of their total expenditures through shared and joint consumption of goods, that wives on average control between one half and two thirds of household resources, and that singles need to spend between one half to three quarters as much as couples to attain the same standard of living for themselves as for the members of a two person household.

\section{Australia}

Australia is similar in many ways to the US and Canada, although it is unique in occupying an entire continent, with its own aboriginal population. British settlers established the first colony in 1788, and even today the interior of Australia is sparsely populated. The South and East coasts boast large cities, with these areas having a prosperous way of life.

The notion that female income-share has significant effects on family expenditure is nothing new in both developed and non-developed countries. Maitra and Ray (2005) provide evidence from Australia of the effect of spousal power on family expenditure patterns, exploiting a useful feature of the collective model, which allows both weights of the spousal utilities to be identified from the data, rather than assumed a priori. In this context, welfare weights are allowed to depend not only on the earnings share, which has been conventionally used, but also on additional variables such as the educational experience of the adults, family income, and family size. The overall message from these results is that the bargaining power of the adult member does affect expenditure patterns, and that the income-pooling hypothesis underlying the unitary model is rejected by the data. The paper provides evidence of non-monotonic relationships between the budget share of an item and the bargaining power, and it is interesting to note that the nature of 
these relationships varies from one specific good to another, according on the male/female power.

\section{Europe}

The Greek culture has had a lasting impact on the West. Much of Europe was later united as part of the Roman Empire, but following its decline and fall, Europe became divided into a series of warring Kingdoms, with their own languages and cultures. Nevertheless, Europe remained united by versions of the Christian religion. The late $15^{\text {th }}$ Century saw Europe become a global leader during the Renaissance, and the region remained the most powerful and technologically advanced for the next five centuries. European nations colonized vast regions of the world and spread their technology and many aspects of their way of life. Europeans then fought two major global wars, but today most of the constituent nations are united in the European Union. European evidence favors the collective model, with relevant countries analyzed in terms of the intra-family balance of power (see, for example, Couprie and Ferrant, 2015, for UK; De Palma, Picard and Ziegelmeyer, 2011, for Germany).

The process by which individual uses of time are transformed into family welfare implies negotiation between the spouses. Couprie and Ferrant (2015) define a family utility function as a weighted sum of family members' individual sub-utility functions, with the family behavior taken to be Pareto-efficient, in such a way that it cannot exist in a family scenario that improves the situation of one spouse without making the situation of the other worse. The authors model and estimate equivalence scales and economies of scale in time use, based on a UK sub-sample that is restricted to singles and couples without children. The results bring important insights on how time use and intra-family bargaining could affect welfare analysis. Two singles living apart require more spare time 
a day to achieve the same utility level as when living in a couple. The welfare derived from individual time use activities tends to be increased by living as a couple, on average. The authors also demonstrate that welfare interactions in time use are at a high level, even when considering pure leisure. A single woman (man) requires 55\% (52\%) of the couple’s time-resources to attain well-being levels similar to those of the couple. Individuals can benefit unequally from economies of scale, such that living in a couple allows time to be saved. A female (male), on average, gains 22 (20) minutes per day of housework and 72 (60) minutes of leisure to attain the same level of well-being, with these savings depending on the characteristics of the couple.

As indicated earlier, a growing literature in economics shows that family financial investments are significantly affected by how decision-making power is allocated between men and women. De Palma, Picard and Ziegelmeyer (2011) report German results on individual and couple choices, in an experiment involving risk. Individuals and couples make binary choices between a lottery and a sure payoff. In the first part of the experiment, spouses are separated and choose independently. Individual choices express individual risk preferences. In the second part of the experiment, male spouses rejoin their partner, and they then make joint choices. In most cases, the woman implemented the couple choices, which express collective risk preferences. The authors investigate the evolution of the balance of power within the family via the individual risk aversions estimated from choices made in the first part of the experiment, to explain the couple's risk aversions estimated from choices made in the second part. The man is initially more successful than the woman in influencing couple choices, but that woman progressively gains power over the course of the decision-making process, and we speculate that part of this power increase relates to the ultimate control over the implementation of joint choices. This evidence on the dynamics of the power balance does not identify whether 
the man or the woman is particularly powerful in specific decisions and, additionally, it suggests that actual decision processes within the family are adaptive and depend on the context.

\section{East-Asia}

While culturally different from the West, East-Asia is far from homogeneous; different groups in East-Asia speak different languages, use different systems of writing, and share distinctive religious beliefs (Confucianism, Taoism, Buddhism, Islam,...). Since opening their economies to foreign investments, this area has undergone an economic revolution, placing the region among the world's fastest-growing economies.

Prior empirical evidence using cross-sectional data has suggested that the balance of power is stable over time. Lee (2007) uses longitudinal data on assignable private consumption in South Korea, to examine the marital balance of power between spouses in a dynamic collective model. The unique data allows the author to account for unobserved heterogeneity at the family level, and time-constant unobserved bargaining power. A comprehensive framework of marriage and intra-family resource allocation suggests that the balance of power is chosen by spousal matching and that it should be robust over time, as long as the marriage is sustained. The income-pooling hypothesis is strongly rejected in the Ordinary Least Squares (OLS) regressions. However, it is not rejected after accounting for unobserved bargaining power. This suggests that relative earning capacities may be a good proxy for the long-term economic development and cultural change balance of power, to an extent that cross-sectional variations in relative earnings across families reflect the pattern of endogenous spousal matching. However, temporal changes in relative earning capacities within a marriage do not appear to induce

any significant resource transfer between spouses. This finding indicates that 
commitment plays a significant role in the dynamics of marital relationships, and allows in particular a significant degree of mutual insurance within the family. It also suggests that, at least in the case of South Korea, as individuals sort themselves into marriages, the balance of power is largely shaped at that moment, and continues to affect intra-family allocations in the long run.

Given that childbirth is an important event for many couples, it is important to analyze how the couple manages the new expenses from childbirth, and how both spouses reduce, or not, their own expenditures. Fujii and Ishikawa (2013) investigate the impact of a new child on intra-household allocation for married Japanese couples, estimating a collective model of the household by using nine rounds of the Japanese Panel Survey of Consumers (JPSC) between 1994 and 2002. Results indicate that the wife's share in private expenditure tends to be lower with more children in the household. Specifically, one additional child is associated with a decrease of at least 2 percentage points in a woman's share of the private goods that are particularly enjoyed by the single individual.

Women in China play a substantial role in caring for ageing parents. Porter (2017) uses the Chinese Longitudinal Healthy Longevity Survey (CLHLS) from 1998 to 2009 to estimate a collective model where the bargaining issue is the time devoted to one's own parents. Evidence shows increases in women's bargaining power due to demographic changes, thus enabling them to provide greater support for their parents and less support for their parents-in-law.

\section{Developed Latin America}

We include evidence from three developed Latin American countries, Mexico, Chile, and Colombia, with all three countries being included in the High Human 
Development category of the UN Human Development Index 2018. The Latin American cultural area received the name because it was once colonized by Spain and Portugal, whose languages are based on Latin. Thus, most Latin Americans speak Spanish or Portuguese, follow the Roman Catholic religion, and share a common history and many traditions.

Rubalcava, Teruel and Thomas (2002) use a cooperative Nash equilibrium to measure the effect in Mexico of a large, exogenous increase in resources attributed to women, relative to the effect of other resources in the family that avoid the complexities associated with modeling labor supply. Holding total household resources constant, an increase in income from PROGRESA (Programa de Educación, Salud y Alimentación) can be interpreted as an increase in the share of total household resources that are attributed to the woman who receives the PROGRESA income. The authors have interpreted this exogenous shift in the attribution of income within the family as being indicative of an increase in the bargaining power of the woman, relative to other family members. Estimation of the effect of this income on spending indicates that, as the share of household resources from PROGRESA increases, the share of the budget spent on children's clothing, education, and a higher quality diet increase. The share of the budget spent on adult clothing, transport, and staples declines. The authors conclude that there has been a shift in the balance of power within PROGRESA families that has resulted in greater investment in the human capital of the next generation. The results suggest that the impact of the income transfers to families has been greater than it would otherwise have been if the income had been given to a male in the family.

The PROGRESA intervention has also been studied by Attanasio and Lechene (2014). They also find that the unitary model is rejected: the program affects expenditure shares even after controlling for the additional resources given to the eligible households. 
Importantly, the authors also find that the relative strength of the family network of household members shapes household choices, supporting the view that several factors, including the importance of social networks, may affect the intra-family balance of power. Last but by no means least, the presence of two 'distribution factors' (variables that affect expenditure shares while not affecting preferences or budget constraints) allows to directly test the efficiency hypothesis of the collective model, which predicts that the two distribution factors should affect expenditure shares in a proportional fashion (Browning, Bourguignon and Chiappori 2009). These authors test the hypothesis using a simultaneous system of demand equations, the Quadratic Almost Ideal Demand System, for food components, and find that this efficiency hypothesis underlying the collective framework is not rejected.

In the same context of political regulations, Chile has changed the law that increased child support rights for children of non-married couples, and Martínez (2013) has taken advantage of this change as a source of exogenous variations in bargaining power within cohabitant families to estimate a non-unitary bargaining model using a panel of cross-sectional data. The author finds a decrease of 1.8 percentage points in fathers' employment, as well as a decrease in their hours worked. Results reject the unitary family model because changes in bargaining power imply changes in family outcomes. These results highlight the importance of considering dynamic family interactions when analyzing the impact of public policies. Even though the legal change should not have had any impact on the income of most cohabiting and married families in the period analyzed, and did not establish a subsidy, family incentives and outcomes changed.

The increase in school attendance of children between 14 and 15 years, after the introduction of the Chilean law, can be interpreted as a movement toward the preferences 
of women in cohabiting relationships, once their bargaining power increased. The 1999 law increased their outside options if the relationship ended, and the evidence is consistent with women using this increase in power to further their children's education. It is important to point out that, although the legal change increased school attendance, it did not affect either mothers' participation in the labor market or their hours of paid work to any significant extent. This could be caused by labor market conditions or by cultural roles that preclude female labor force participation. If children are more likely to be in school and mothers do not increase their work participation, it is likely mothers would have more free time, which would increase their utility, providing that they value leisure. This article shows that this legal change can increase children's well-being through indirect channels, including improving women’s bargaining power.

Campaña, Giménez-Nadal and Molina (2018) use time diary data from Mexico (2009) and Colombia (2012) to estimate the collective model of labor supply to evaluate, among other factors, whether intra-household bargaining power is an important variable on the labor supply decisions of spouses. In doing so, they use the gender ratio (the number of men per 100 women) as the distribution factor within households, and the Generalized Method of Moments (GMM) estimator is used to estimate the model. Results point to the validity of the collective model in both countries, in such a way that efficient labor supply decisions are taken. Furthermore, higher female salaries are related to more labor market hours of female workers, cross-wages are negatively related to the labor supply of workers (male wage with respect to female labor supply, and vice versa), and an increase in the male's wage rate of workers in Colombia significantly impacts the nonlabor income of female workers. Gender-ratios are related to transfers of additional income from male to female workers in Colombia. The presence of children is negatively 
related to the labor supply of female workers in Mexico, while in Colombia the presence of other household members over age 18 is positively related to the female labor supply.

\section{South Africa}

Another strong rejection of the unitary model is provided by Duflo (2003), who analyzes a reform of the South African social pension program for elderly that extended the benefits to a large, previously not covered black population. Due to eligibility criteria, the coverage is not universal; in some households, only one of the grandparents receives the benefit. Duflo uses a difference in difference approach based on the demographics of the siblings to control for selection in eligibility. She shows that the recipient's gender a typical distribution factor - is of considerable importance for the impact of the transfers on children's health: a payment to the grandfather has no significant effect, whereas the same amount paid to the grandmother results in a huge improvement in the health status of girls in the family.

\section{Indonesia}

Southeast Asia has been strongly influenced by the large influx of peoples from China and India, as well as the Middle East and remnants from the European Colonial powers. The islands of Southeast Asia export important spices - pepper, cinnamon, nutmeg, and so on - used in cooking all over the world. In earlier times, these spices were highly prized in Europe and the Middle East, as they provided a means of preserving food that was more flavorful than salt alone. Although much of the region continues to follow traditional ways of life, the growth of cities, the spread of technology, and government modernization programs are making inroads into traditional village life. It is well-known that control of economic resources is an important source of power in negotiating family decisions. In this context, Thomas, Contreras and Frankenberg (2002) examine the effects 
of maternal and paternal assets in marriage, in Indonesia, on whether children experience coughs, fevers, diarrhea, or other symptoms in the month prior to the interview. The authors argue that, conditional on income, the assets that husbands and wives bring to the marriage are measures of the power each partner wields within the marriage. An exploration of the morbidity data in the Indonesian Family Life Survey (IFLS) suggests that reporting errors in morbidities may be correlated with parental characteristics. Examination of the data on assets at marriage suggests that reported values are also likely to contain errors. The authors address these issues by including household fixed effects in the preferred specification. Results indicate that mothers who are more powerful allocate resources towards goods and services that they value differently from their husbands, and this is reflected in their sons having fewer episodes of illness than their daughters. Since the unitary model does not appear to adequately characterize Javanese and Sumatran families, the authors examined the implications of the assumption that the allocations are Pareto efficient. The model predicts that the ratio of the effect of paternal assets to the effect of maternal assets will be constant across morbidities. That prediction is not rejected by the data, leading to the conclusion that although couples may not agree about resource allocations, they cannot reallocate resources in such a way that one family member is made better-off without making at least one other family member worse-off. 


\section{THE INTRA-FAMILY BALANCE OF POWER: CROSS- CULTURAL EVIDENCE IN NON-DEVELOPED AREAS}

The analysis of the intra-family balance of power is particularly important in developing regions, given the underlying cultural norms that persist today. We have identified two cultural non-developed areas that exhibit a bottom-medium or low HDI, (South-Asia and Sub-Saharan Africa) where relevant economic analyses of spouses' power have been developed from a non-unitary perspective.

\section{South-Asia}

The Himalayas have allowed populations on each side of the mountains to develop their own distinct languages, customs, and cultures. In ancient times, invaders introduced the Hindu religion and caste system. In the $18^{\text {th }}$ century, much of India fell under British rule. When India became independent, in 1947, it was partitioned into Hindu India and Moslem Pakistan, and then the former East Pakistan became Bangladesh. The majority of the populations speak English, as well as Hindi and other local languages.

We first consider some evidence for the case of Asia. Koolwal and Ray (2002), using data from Nepal, estimate a collective framework and find that the woman's share of family earnings derived from paid employment, excluding the unearned income, understates her true power in influencing family outcomes. Other interesting results indicate that rural women enjoy greater power within the family than their urban counterparts, and that education plays an effective role in enhancing the power of women inside the family. These estimates of the female power equation provide considerable support for the hypothesis that welfare weights should be estimated simultaneously with household outcomes. The statistical significance of the impact of female power on an 
item's budget share provides a convenient test of the income-pooling hypothesis underlying the unitary model. The results provide little evidence in support of income pooling, especially for items that have the characteristics of a private good, in being primarily consumed by particular family members (e.g. tobacco and alcohol are consumed, almost exclusively, by the adult male). Note, however, that limited support for income pooling does exist for items that are collectively consumed within the family (e.g. flour and rice, eggs and milk, and meat are jointly consumed within the household). The results reveal certain non-monotonic relationships between female power and budget share that vary a good deal from item to item.

A related investigation by Rossela Calvi (2019) documents the well-known ‘missing women' phenomenon, initially documented by Amartya Sen (1990). The starting point is the fact that a majority of missing Indian women die in adulthood. Calvi's explanation is that women of post-reproductive age experience a decline in their health condition and a consequent surge in mortality risk that is directly related to changes affecting their intra-household bargaining power. She exploits amendments to the Indian inheritance law as a natural experiment. The Hindu Succession Act amendments equalized women’s inheritance rights to men’s in several Indian states between 1976 and 2005. By granting women the right to inherit their natal family property, these reforms likely strengthened their bargaining position in their marital families. Using data from the 2005-2006 National Family Health Survey and the 2004 NSS Morbidity and Health Care Survey, she show that women's exposure to these reforms improves their nutritional outcomes (measured by body mass index and anaemia), reduces their likelihood to suffer from a variety of ailments, and lowers their risk of death.

An important consequence of power relationships within the family is the measure of intra-family inequality. Brown, Calvi and Penglase (2019) argue that standard anti- 
poverty policies, which typically target poor households, may be in part misdirected because many poor individuals reside in non-poor households. Using Bangladeshi data, they show that undernourished individuals are spread across the household per-capita expenditure distribution. In particular, women, children, and the elderly face significant probabilities of living in poverty even in households with per-capita expenditure above the poverty threshold.

Basu and Ray (2002) use the collective framework to add evidence for the case of Nepal of the relationship between the balance of power in the family between the husband and the wife and its impact on child labor. The results derived in the paper show that child labor is less likely when power is evenly balanced between the spouses. While prior studies have shown that higher parental education makes child labor less likely, Basu and Ray's study shows that there are greater subtleties involved in this relationship. While it may be better, ceteris paribus, to have higher-educated adults, the incidence of child labor is kept at its lowest by achieving a more balanced level of education among the parents. Since most developing countries are characterized by a disproportionately low level of education and literacy among women, this study provides additional reasons why female education ought to be emphasized in developing countries.

Maitra and Ray (2005) use data from Pakistan to revisit the notion of resourcepooling from different sources, accruing to different members, in order to achieve a range of family outcomes. The study extends an earlier work (Maitra and Ray, 2003) by introducing gender-based disaggregation of resource inflows. Analyses show that the source of the resource does matter for the expenditure outcome, and that the different resource inflow variables have significantly different impacts on the variables of interest, that is to say, the expenditure shares. The identity of the resource recipient within the family also affects the outcome. There are significant differences between poor and non- 
poor families in terms of how resource inflows interact with each other, and how they affect family expenditure patterns.

The most important results of this paper include the following. First, each income stream is distinguished by the gender of the income recipient, in line with the spirit of non-unitary family models that has characterized much of the recent literature on family behavior. Second, the authors distinguish between the different sources of non-labor income, namely, unearned income and private remittances that have been lumped together in previous studies. Moreover, they recognize the joint endogeneity of such resource inflows in the tests of income pooling. Third, following from the two issues raised above, the authors test the hypothesis of income pooling, not only between men and women, as several studies have recently done, but also, pooling of the two components of non-labor earnings, mentioned above, separately for men and for women.

Does the power of an individual making family decisions have an impact on that family’s expenditure pattern? To answer this question, Lancaster, Maitra and Ray (2006) use the collective approach to examine whether relative spousal power, measured by her/his income share, has an effect on family patterns. The authors propose and estimate, for the case of India, a framework of this type. Empirical results using family-level unit record data-sets provide considerable support for the idea that the welfare weights, i.e. the bargaining power, are significantly affected by changes in the family's socioeconomic status.

Consistent with recent empirical evidence, the study rejects an important implication of the unitary household model, namely that the identity of the income recipient is irrelevant in the determination of the family's expenditure outcomes. Also, the study finds that such rejections are either marginal or do not occur for some of the 
smaller items of expenditure, especially those, such as Alcohol and Tobacco, that are privately consumed (typically by adult males) within the household. However, results generally point to more complex relationships between the family’s expenditure outcome and the intra-household balance of power than is commonly appreciated in the literature. Results also suggest that an even spread of power is most likely to be found in a family where educational experience itself is spread evenly between the spouses. Thus, promoting both male and female levels of education within the family, as a way to improve both partners' income earnings opportunities, will help to prevent an overwhelming dominance by one partner in the decision-making process.

\section{Sub-Saharan Africa}

The area of Africa south of the Sahara Desert, with its different climate, topography, and non-Arab populations, forms a separate and distinct cultural region. Most of the region has a warm climate, and many peoples in this area were once afflicted by the slave trade, or otherwise subject to European colonial rule. Populations remain divided into a large number of separate ethnic groups, or tribes, each with its own language and culture, although they often share similar religious beliefs. Africans have been influenced by both Islam and Christianity, as well as by local animist traditions.

A first line of research addresses intra-family inequality. Using semiparametric restrictions on individual preferences within a collective model, Dunbar, Lewbel and Pendakur (2013) The share of household resources devoted to children is hard to identify, because consumption identify how total household resources are divided up among household members, by observing how each family member's expenditures on a single private good like clothing varies with income and family size. Using data from Malawi they show how resources devoted to wives and children vary by family size and structure. 
In particular, standard poverty indices, which implicitly assume a fair allocation of resources within the household, seriously understate the incidence of child poverty.

Finally, while most studies do not reject the Pareto efficiency hypothesis, Udry (1996) reaches a different conclusion analyzing agricultural production in Burkina Faso. Using plot-level agricultural data from households, he concludes that the allocation of resources within these African households is Pareto inefficient; specifically, he finds that among plots planted with the same crop in the same year within a given household, those controlled by women produce lower yields than the men's plots, suggesting an inefficient allocation of inputs (notably fertilizers). These conclusions have however been qualified by Akresh (2005), who, using an alternative nationally representative dataset, finds that only households in regions geographically proximate to those studied by Udry exhibit Pareto inefficient intrahousehold allocations, while the rest of the country reveals no evidence of Pareto inefficiencies. Moreover, households in regions experiencing negative rainfall shocks are on average less likely to exhibit Pareto inefficient intrahousehold allocations, and these negative rainfall shocks are correlated with increases in labor resources allocated to the wife's plots, further confirming that in bad years, households try to avoid losses from Pareto inefficiency.

\section{DISCUSSION AND CONCLUSIONS}

This paper provides an overview of the cross-cultural evidence for the intramarriage balance of power on the basis of the non-unitary approach. In addition to the literature in sociology and anthropology arguing that spousal power is important in the 
analysis of family behavior, the economic evidence has recently increased in the context of the collective models. This framework assumes that a family maximizes a weighted average of the wife's and husband's utilities, where the weights capture each agent's power or effectiveness in the decision-making process.

Throughout the paper, we have presented recent international evidence on the intra-family balance of power for a variety of cultural areas. We have identified cultural regions as geographical areas in which individuals share common cultural characteristics, focusing on seven developed cultural areas: United States and Canada, Australia, Europe, East-Asia, Latin America, South Africa and Indonesia, and two broad non-developed areas: South-Asia and Sub-Saharan Africa, where important economic analyses of spousal power have been carried out from a collective perspective.

Several conclusions emerge from this broad overview:

- Empirical investigations clearly indicate that, in both developed and nondeveloped cultural areas, the 'unitary' representation of the household, which assumes that the household behaves as a single decision-maker, does not provide an accurate description of actual behavior. In particular, income pooling, a central prediction of the unitary framework, has been repeatedly rejected. Consequently, non-unitary models, in which intra-family bargaining and the notion of respective powers play an important role, are by now widely accepted

- The Pareto-optimality hypothesis of collective models has been generally accepted by empirical studies. While some violations have been pointed out (for instance in Udry's 1996 paper), they seem to constitute exceptions; efficiency appears to be not only a natural benchmark, but also, in many case, an acceptable description of actual behavior. 
- Regarding the (few) violations of efficiency, not much is known on the ultimate cause of observed inefficiencies. A natural but somewhat ad-hoc justification could invoke social norms. Alternatively, inefficiencies may stem from informational problems (asymmetric information, imperfect monitoring, ...) within the household; yet another cause could be limitations to the spouses' ability to commit on future behavior. Clearly, more work is needed on this important issue. $^{2}$

- Within the efficiency paradigm, the collective model allows to structurally analyze issues such as household formation and dissolution or the impact of policies 'targeting' specific household members (e.g., women or children), that the standard, 'unitary' approach was essentially disregarding. Of particular importance is the notion of intra-household inequality. The traditional analysis, based on equivalence scales, was essentially assuming an equal (or 'fair') allocation of resources within the family - a view that is both unrealistic and dangerously misleading. On the contrary, the collective approach - and specifically the notion of indifference scale - recognizes the endogenous nature of resource allocation within the family, and provides empirical tools aimed at quantifying the resulting, intra-family inequality.

- In particular, both developed and developing countries and regions provide direct evidence that the respective bargaining powers of the adult members do affect expenditure patterns. The specific translation relates to a number of family decisions (expenditures, time uses at home, paid work, charity donations, wealth accumulation, childbirth and elder care, among many others); moreover, it varies widely across cultures. For instance, increasing women's power through targeted

\footnotetext{
${ }^{2}$ On the latter point, see for instance Chiappori and Mazzocco (2017).
} 
transfers ultimately benefits daughters in South Africa (Duflo 2003); in Ethiopia, however, mothers with more assets invest preferentially in sons, while in Bangladesh, fathers' and mothers' assets do not have differential effects on daughters relative to sons (Quisumbing. and Maluccio 2003).

- Similarly, the determinants of the spouses' respective bargaining powers strongly depend on the cultural and socio-economic context. In Western economies, human capital, wealth and incomes, as well as global factors such as sex ratios or laws governing divorce and separation, have been empirically linked to individual decision power. In developing countries, relevant factors also include, at least in some contexts, religion, ethnicity, cast, family background and many other determinants. In fact, the same general mechanism - individual bargaining powers playing a crucial role in determining household behavior - operates in very specific ways depending on the cultural context.

- Yet in basically all situations, age and especially education appear to play an important role. In particular, fair allocation is more likely to occur in a family where education and human capital is spread evenly between the spouses.

On this last point, recent evolutions provide strong motives for optimism. In basically all developed economies, and actually in an increasing number of developing ones, women are now more educated than men. We confidently predict that this evolution will deeply affect, for the better, economic and social welfare. 


\section{REFERENCES}

Andreoni J., Brown, E., and Rischall, I. (2003). Charitable giving by married couples. Who decides and why does it matter? Journal of Human Resources 38: 111-133.

Attanasio, O., and Lechene, V. (2002). Tests of income pooling in household decisions. Review of Economic Dynamics 5: 720-748.

Basu, K. (2006). Gender and say: a model of household behaviour with endogenously determined balance of power. Economic Journal 116(511): 558-580.

Basu, K. and Ray, R. (2002). The collective model of the household and an unexpected implication for child labor. Policy Research Working Paper 2813. The World Bank.

Becker, G.S. (1981). A Treatise on the Family, Enl. Edition. Cambridge: Cambridge University Press.

Bergstrom, Theodore C., .A Fresh Look at the Rotten Kid Theorem and Other Household Mysteries., Journal of Political Economy, 97 (1989), 1138-1159.

Bergstrom, T. (1997). A survey of theories of the family. In M.R. Rosenzweig and O. Stark (eds), Handbook of Population and Family Economics. Amsterdam, North-Holland.

Blumberg, R. and Coleman, M. (1989). A theoretical look at the gender balance of power in the American couple. Journal of Family Issues 10: 225-250. 
Brown, C., R. Calvi and J. Penglase (2019), 'Sharing the Pie: Undernutrition, IntraHousehold Allocation, and Poverty, SSRN, https://ssrn.com/abstract=3199129

Browning, M., and Chiappori, P.A. (1998). Efficient intra-household allocations: a general characterization and empirical tests. Econometrica 66: 1241-1278.

Browning, M., Chiappori, P.A., and Lewbel, A. (2013). Estimating consumption economies of scale, adult equivalence scales, and household bargaining power. The Review of Economic Studies 80: 1267-1303.

Browning, M., P.A. Chiappori and Y. Weiss (2014), Economics of the Family, Cambridge University Press, Cambridge.

Calvi, R. (2019), 'Why Are Older Women Missing in India? The Age Profile of Bargaining Power and Poverty’, Journal of Political Economy, forthcoming.

Campaña, J.C., Giménez-Nadal, J.I. and Molina, J.A. (2018). Efficient labor supply for Latin families: is the intra-household bargaining power relevant? IZA DP $\mathrm{N}^{\circ}$ 11695.

Chiappori, P.A. (1988). Rational household labor supply. Econometrica 56: 63-89.

Chiappori, P.A. (1992). Collective labour supply and welfare. Journal of Political Economy 100: 437-467.

Chiappori, P.A., and M. Mazzocco, "Static and Intertemporal Household Decisions" (with M. Mazzocco), Journal of Economic Literature, 2017, 55(3), 1-61 
Couprie, H., and Ferrant, G. (2015). Welfare comparisons, economies of scales and equivalence scale in time use. Annales d’Économie et de Statistique 117-118: 185-210.

Desai, S. and Jain, D. (1994). Maternal employment and family dynamics: The social context of women's work in rural South India. Population and Development Review 20: 115-136.

Donni, O., and Chiappori, P.A. (2011). Non-unitary models of household behavior: a survey of the literature. In: Molina, J.A. (ed.). Household Economic Behaviors. Berlin: Springer Verlag.

Donni, O. and Molina, J.A. (2018). Household collective models: three decades of theoretical contributions and empirical evidence. IZA DP Nº 11915.

Duflo, E., (2003). Grandmothers and granddaughters: old age pension and intrahousehold allocation in South Africa. World Bank Economic Review 17(1): 125.

Dunbar, G. R., A. Lewbel, And K. Pendakur (2013): “Children’s Resources in Collective Households:Identification, Estimation, and an Application to Child Poverty in Malawi,” American Economic Review, 103, 438-71.

Fujii, T. and Ishikawa, R. (2013). How does childbirth alter intra-household resource allocation? Evidence from Japan. Oxford Bulletin of Economics and Statistics, 75(3), 362-387.

Gupta, A. and Ferguson, J. (1997). Culture, Power, Place: Explorations in Critical Anthropology. Durham, NC: Duke University Press. 
Hoddinott, J. and Haddad, L. (1995). Does female income share influence household expenditures? Evidence from Côte d'Ivoire. Oxford Bulletin of Economics and Statistics 57: 77-96.

Kanbur, R. and Haddad, L. (1994). Are better off households more unequal or less unequal: A bargaining theoretic approach to "Kuznets" effects at the micro level. Oxford Economic papers 46(3): 335-458.

Koolwal, G. and Ray, R. (2002). Estimating the endogenously determined intrahousehold balance of power and its impact on expenditure pattern. Policy Research Working Paper 2814. The World Bank.

Konrad, K. A. and Lommerud, K.E. (1995). Family policy with non-cooperative families. The Scandinavian Journal of Economics 97: 581-601.

Kousta, S. (2019). Why gender gaps persist. Nature Human Behaviour. DOI: $10.1177 / 0001839219832310$.

Lakshmanasamy, T. (2003). Testing the unitary and Nash bargaining household models in India. Journal of Social and Economic Development 5: 197-217

Lancaster, G., Maitra, P., and Ray, R. (2006). Endogenous intra-household balance of power and its impact on expenditure patterns: Evidence from India. Economica 73: 435-460.

Lee, J. (2007). Marriage, the sharing rule, and pocket money: The case of South Korea, Economic Development and Cultural Change 55: 557-581.

Lundberg, S., and Pollak, R. (1994). Noncooperative bargaining models of marriage. American Economic Review Papers \& Proceedings 84: 132-137. 
Lundberg, S., Pollak, R.A., and Wales, T.J. (1997). Do husbands and wives pool their resources? Evidence from the United Kingdom child benefit. Journal of Human Resources 32: 463-480.

Lundberg, S., and Ward-Batts, J. (2004). Saving for retirement: Household bargaining and household net worth. Claremont McKenna College Robert Day School of Economics and Finance Research Paper No. 2004-03.

Maitra, P. and Ray, R. (2002). Household resources, expenditure patterns and resource pooling: evidence from South Africa. Mimeo. University of Tasmania.

Maitra P., and Ray, R. (2003). The effect of transfers on household expenditure patterns and poverty in South Africa. Journal of Development Economics 71(1): 23-49.

Maitra P. and Ray, R. (2005). An integrated test of the unitary household model: evidence from Pakistan. ABERU DP 7. Monash University.

Maitra P., and Ray, R. (2005). The impact of intra-household balance of power on expenditure pattern: The Australian evidence. Australian Economic Paper 44: 15-29.

Manser, M. and Brown, M. (1980). Marriage and household decision making: a bargaining analysis. International Economic Review 21(3): 31-44.

McElroy, M. and Horney, M. (1981). Nash bargained household decisions. International Economic Review 22(2): 333-350.

Martínez, C. (2013). Intrahousehold allocation and bargaining Power: Evidence from Chile, Economic Development and Cultural Change 61: 577-605. 
de Palma, A., Picard, N., and Ziegelmeyer, A. (2011). Individual and couple decision behavior under risk: evidence on the dynamics of power balance. Theory and Decision 70: 45-64.

Phipps, S.A., and Burton, P. (1998). What's mine is yours? The influence of male and female incomes on patterns of household expenditure. Economica 65: 599-613.

Pollak, R.A. (1994). For better or worse: The roles of power in models of distribution within marriage. American Economic Review: papers and Proceedings 84(2): 148-152.

Porter, M. (2017). Spousal bargaining over care for elderly parents in China: Imbalances in sex ratios influence the allocation of support. The Journal of Development studies, 53(4), 514-529.

Quisumbing. A.R., and Maluccio, J.A. (2003). Resources at marriage and intrahousehold allocation: evidence from Bangladesh, Ethiopia, Indonesia and South Africa. Oxford Bulletin of Economics and Statistics 65: 283-327.

Riley, N. (1997). Gender, power and population change. Population Bulletin 52: 1-46.

Rubalcava, L., Teruel G., and Thomas, D. (2002). Welfare design, women's empowerment and income pooling. Documento de Trabajo 244. CIDE (Centro de Investigatión y Docencia Económicas).

Samuelson, P. (1956). Social Indifference Curves. Quarterly Journal of Economics, 70: $1-22$

Schultz, T.P. (1990). Testing the neoclassical model of family labor supply and fertility. Journal of Human Resources 25: 599-631. 
Sen, A. (1990): “More Than 100 Million Women Are Missing,” New York Review of Books, pp. 61-66.

Slatton, B.C., Brailey, C.D. (2019). Women and Inequality in the 21st Century. Routledge, Taylor \& Francis Group.

Thomas, D. (1990). Intra-household Resource Allocation: An inferential approach. Journal of Human Resources 25: 635-664.

Thomas, D., Contreras, D., and Frankenberg, E. (2002). Distribution of power within the household and child health. Mimeo. University of California at Los Angeles.

UN Human Development Index (2018). Global Human Development Indicators. United Nations Development Programme.

Yilmazer, T., and Lich, S. (2015). Portfolio choice and risk attitudes: a household bargaining approach. Review of Economics of the Household 13: 219-241. 
Table 1. Chronological evidence on the intra-marriage balance of power

\begin{tabular}{|c|c|c|c|c|}
\hline Year & Authors & Country & Data & Keywords \\
\hline 2002 & $\begin{array}{l}\text { Basu and } \\
\text { Ray }\end{array}$ & Nepal & NLSS/1995 & $\begin{array}{l}\text { Balance of Power } \\
\text { Child Labor } \\
\text { Woman's Power }\end{array}$ \\
\hline 2002 & $\begin{array}{l}\text { Rubalcava, } \\
\text { Teruel and } \\
\text { Thomas }\end{array}$ & Mexico & PROGRESA & $\begin{array}{l}\text { Woman's Power } \\
\text { Consumption Time } \\
\text { Welfare }\end{array}$ \\
\hline 2002 & $\begin{array}{c}\text { Thomas, } \\
\text { Contreras } \\
\text { and } \\
\text { Frankenberg }\end{array}$ & Indonesia & IFLS/1993-97 & $\begin{array}{c}\text { Relative Power } \\
\text { Intra-Family Child } \\
\text { Health }\end{array}$ \\
\hline 2003 & $\begin{array}{l}\text { Andreoni, } \\
\text { Brown and } \\
\text { Rischall }\end{array}$ & US & $\begin{array}{l}\text { Gallup } \\
\text { Organization/ } \\
\text { 1992-94 }\end{array}$ & $\begin{array}{l}\text { Charitable Giving } \\
\text { Bargaining } \\
\text { Relative Power }\end{array}$ \\
\hline 2003 & Duflo & South Africa & $\begin{array}{l}\text { SALDRU/ } \\
1993\end{array}$ & $\begin{array}{l}\text { Public Transfers } \\
\text { Programs } \\
\text { Spousal Recipient }\end{array}$ \\
\hline 2003 & $\begin{array}{l}\text { Maitra and } \\
\text { Ray }\end{array}$ & Australia & AHES/1998-99 & $\begin{array}{l}\text { Spousal Power } \\
\text { Expenditure Intra- } \\
\text { Family }\end{array}$ \\
\hline 2003 & $\begin{array}{l}\text { Quisumbing } \\
\text { and Maluccio }\end{array}$ & $\begin{array}{l}\text { Bangladesh, } \\
\text { South Africa, } \\
\text { Ethiopia, } \\
\text { Indonesia, }\end{array}$ & $\begin{array}{l}\text { Various/1996- } \\
1998\end{array}$ & $\begin{array}{c}\text { Marriage } \\
\text { Intra-family } \\
\text { Bargaining Power }\end{array}$ \\
\hline 2004 & $\begin{array}{l}\text { Lundberg } \\
\text { and Ward- } \\
\text { Batts }\end{array}$ & US & HRS/1992 & $\begin{array}{l}\text { Bargaining } \\
\text { Spouses’ Control } \\
\text { Net Worth }\end{array}$ \\
\hline 2005 & $\begin{array}{l}\text { Maitra and } \\
\text { Ray }\end{array}$ & Australia & AHES1998-99 & $\begin{array}{l}\text { Simultaneous } \\
\text { Expenditure } \\
\text { Bargaining Power }\end{array}$ \\
\hline 2006 & $\begin{array}{l}\text { Lancaster, } \\
\text { Maitra and } \\
\text { Ray }\end{array}$ & India & NSS/1993-94 & $\begin{array}{l}\text { Endogeneity } \\
\text { Bargaining Power } \\
\text { Expenditure }\end{array}$ \\
\hline 2007 & Lee & South Korea & KHPS/1993-98 & $\begin{array}{c}\text { Consumption Spouses } \\
\text { Power Dynamic }\end{array}$ \\
\hline 2011 & $\begin{array}{l}\text { de Palma, } \\
\text { Picard and } \\
\text { Ziegelmeyer }\end{array}$ & Germany & Sessions/2005 & $\begin{array}{l}\text { Balance of Power } \\
\text { Experiments } \\
\text { Intra-Family }\end{array}$ \\
\hline 2013 & $\begin{array}{l}\text { Browning, } \\
\text { Chiappori } \\
\text { and Lewel }\end{array}$ & Canada & $\begin{array}{l}\text { FAMEX/1974- } \\
\text { 1992) }\end{array}$ & $\begin{array}{c}\text { Consumption } \\
\text { Economies of Scale } \\
\text { Bargaining Power }\end{array}$ \\
\hline
\end{tabular}


Childbirth

Intra-household

Expenditure Share

2013

Martínez

Chile

CASEN/1990-

Intra-family

92-94-96-2000 Bargaining Power

2015

Couprie and

Ferrant

UK

UKTUS/2000

Welfare

Time Use

Bargaining Power

2015

Yilmazer and

US

HRS/1992-2006

Portfolio Choice

Lich

Risky Assets

Bargaining Power

2017

Porter

China

CLHLS/

1998-2009

Spousal Bargaining Care

Elderly Parents

Campaña,

2018

Giménez-
Nadal and
Molina

Mexico

Time Use

Efficiency

Surveys:

Colombia

Mexico (2009)

Labor Supply

Time Use

Colombia(2012) Bargaining Power 